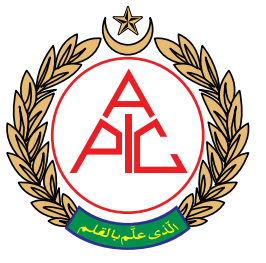
Department of Anesthesiology, Mysore Medical College and Research Institute, Mysuru570001, Karnataka, India ${ }^{2}$ Assistant Professor, Department of Anesthesiology, Mysore Medical College and Research Institute, Mysuru570001, Karnataka, India ${ }^{3}$ Resident, Department of Anesthesiology, Mysore Medical College and Research Institute, Mysuru-570001, Karnataka, India

Correspondence: Dr Shalini Anand,

406, Bougain Villa, Sankalp Central Park

Old Jawa Main Road, Yadavagiri, Mysuru-570020, Karnataka, India

E-mail:

shalinianand20@gmail.com Phone: +91 9986061614

Received - 4 December 2019;

Reviewed - 18 January 2020;

Revised - 15 January 2020;

Accepted - 12 February 2020

\section{Comparative study of isobaric levobupivacaine and hyperbaric bupivacaine for subarachnoid block in elective cesarean sections}

\author{
Dinesh Govinda Rao ${ }^{1}$, Shalini A. ${ }^{2 *}$, Nayaz Pasha ${ }^{3}$
}

\begin{abstract}
Background \& Objective: Hyperbaric bupivacaine $0.5 \%$ with fentanyl is often used for spinal anesthesia in lower segment cesarean section (LSCS). Its cardiotoxicity, extended sensory block and high sympathetic blocks in parturients can be disadvantageous. Levobupivacaine, an s-enantiomer of racemic bupivacaine is truly isobaric with CSF. It should be able to produce adequate sensory block with less hemodynamic changes and less cardiovascular toxicity. We aimed to evaluate the clinical efficacy of intrathecal $0.5 \%$ isobaric levobupivacaine compared to $0.5 \%$ hyperbaric bupivacaine with fentanyl $25 \mu \mathrm{g}$ for elective LSCS.
\end{abstract}

Methodology: In this prospective, randomized, double blind study, 60 parturients with ASA physical status I-II, scheduled for elective LSCS were divided into 2 groups ( $\mathrm{n}=30$ each ). Each group received either $8 \mathrm{mg}$ of $0.5 \%$ isobaric levobupivacaine $+25 \mu \mathrm{g}$ fentanyl (Group-L) or $8 \mathrm{mg}$ of $0.5 \%$ hyperbaric bupivacaine $+25 \mu \mathrm{g}$ fentanyl (Group-B). Sensory and motor block characteristics of both groups were assessed with pinprick and Bromage scale; neonatal APGAR scores, hemodynamic changes and side effects, if any, were recorded. The data were statistically analyzed with appropriate tests.

Results: Onset of sensory blockade was slower and two segment regression time was prolonged with isobaric levobupivacaine $(p<0.001)$. However, it produced adequate surgical anesthesia with shorter motor blockade and lesser hemodynamic disturbances compared to hyperbaric bupivacaine. Postoperative analgesia and neonatal outcomes were comparable in both the groups. Adverse effects were less in the levobupivacaine group.

Conclusion: Intrathecal isobaric levobupivacaine with fentanyl combination is a useful alternative to hyperbaric bupivacaine for elective LSCS with better hemodynamic stability.

Key words: Cesarean section; Fentanyl; Bupivacaine; Levobupivacaine; Spinal anesthesia

Citation: Rao GD, Shalini A, Pasha N. Comparative study of isobaric levobupivacaine and hyperbaric bupivacaine for subarachnoid block in elective cesarean sections. Anaesth. pain intensive care 2020;24(2):215-222

DOI: https://doi.org/10.35975/apic.v24i2.1258

\section{INTRODUCTION}

Cesarean section is one of the most common surgical procedures in obstetrics. ${ }^{1}$ Pregnancy is usually associated with difficult airway and general anesthesia puts the parturients at an increased risk of regurgitation and pulmonary aspiration of gastric contents leading to acid aspiration syndrome, which is a major cause of morbidity and mortality. ${ }^{2}$

Regional anesthesia, especially subarachnoid block, with local anesthetics is easy to administer, safe and reliable. It allows for adequate level of analgesia and relaxation to be established rapidly. ${ }^{2}$ Avoidance of polypharmacy ${ }^{3}$, improved maternal satisfaction and 
good postoperative analgesia facilitate early breastfeeding and establishment of bond between mother and baby; giving regional anesthesia a distinct advantage over general anesthesia. ${ }^{1,4}$

To prevent maternal discomfort during Lower segment cesarean section (LSCS), dermatomal analgesia up to T4 is needed. ${ }^{2}$ This high spinal level may cause hypotension and impair placental perfusion. If the volume of local anesthetic agent is reduced to avoid hypotension, it may lead to visceral pain during procedure and reduced postoperative analgesia. ${ }^{5}$ Opioids such as morphine, fentanyl, sufentanil and buprenorphine have been administered as intrathecal adjuvants for reducing intraoperative visceral pain experienced by parturients during handling of uterus. ${ }^{6}$ Intrathecal fentanyl, in addition to providing prolonged post-operative analgesia, also allows the reduction of dose of local anesthetic, which contributes to more stable hemodynamics as it produces a synergistic effect without increasing sympathetic blockade. ${ }^{5}$

Intrathecal Lidocaine has been implicated in transient neurologic irritation and cauda equina syndrome. ${ }^{7}$ Bupivacaine $0.5 \%$ is the most extensively used intrathecal local anesthetic because of its longer duration of motor and sensory blockade. ${ }^{8}$ Dextro enantiomer in commercial bupivacaine is responsible for cardiotoxicity. ${ }^{9}$ Levobupivacaine (S-1-butyl-2piperidylformo-2',6'-xylidide hydrochloride) being the pure $\mathrm{S}(-)$ enantiomer of racemic parent drug has pharmacodynamic properties similar to it but has lower incidence of systemic toxicity than bupivacaine. ${ }^{9,10}$

We conducted this study to evaluate the characteristics of subarachnoid block with levobupivacaine in elective LSCS and compare it with bupivacaine. The adjuvant used with both drugs was fentanyl.

\section{METHODOLOGY}

Sixty parturients, 18-30 years of age, American Society of Anesthesiologists (ASA) physical status I or II, with > 36 weeks gestation, undergoing elective LSCS for a singleton baby under subarachnoid block in our hospital were enrolled. Institutional ethical committee approval was obtained.

Parturients with an obstetric complication, a coexisting medical disease e.g., anemia, heart disease, gestational hypertension, and gestational diabetes mellitus, any contraindication to spinal anesthesia or history of hypersensitivity to the study drugs were not included in the study. A detailed pre-anesthetic evaluation was done for all parturients on the evening before surgery and written informed consent was taken. All parturients were premedicated on the night before surgery with tab ranitidine $150 \mathrm{mg}$. They were transported to the operating room in left lateral position.

Study population was randomly allocated to two groups with 30 parturients in each group by shuffled sealed opaque envelope method. All subjects were infused with $500 \mathrm{ml}$ of ringer lactate solution, $30 \mathrm{~min}$ before spinal anesthesia. Acid aspiration prophylaxis was given before surgery.

Lumbar puncture was performed in the right lateral decubitus position at the level of L3-L4 interspace through a midline approach using 25G Quincke spinal needle in both the groups and the study drug was injected into the theca as follows;

Group-B: $0.5 \%$ hyperbaric bupivacaine $8 \mathrm{mg}$ $(1.6 \mathrm{ml})+$ fentanyl $25 \mu \mathrm{g}(0.5 \mathrm{ml})$.

Group-L: $0.5 \%$ isobaric levobupivacaine $8 \mathrm{mg}$ $(1.6 \mathrm{ml})+$ fentanyl $25 \mu \mathrm{g}(0.5 \mathrm{ml})$.

The test drugs were loaded in a $3 \mathrm{ml}$ syringe by an anesthesiologist who was not a part of the study. Subarachnoid block was given to all by the observer anesthesiologist. Thus both the observer and the subjects were blinded to the study drugs. Patients were turned supine with a wedge under the right hip. Supplemental oxygen was given through a face mask.

Sensory blockade was monitored with a blunt $27 \mathrm{G}$ hypodermic needle every $15 \mathrm{sec}$ till the onset of sensory blockade and thereafter at 2 min intervals, till the maximum level of sensory 
blockade was achieved and subsequently at 5 min interval during first $30 \mathrm{~min}$, then at $15 \mathrm{~min}$ intervals between 30 and $120 \mathrm{~min}$, and thereafter at $30 \mathrm{~min}$ intervals until complete recovery. Surgery was allowed to start once the sensory level reached to T6 dermatome.

Time taken to achieve highest level of sensory blockade was taken as the time from the injection of the study drug to the maximum sensory blockade attained. Two segment sensory regression time was defined as the time taken from the maximum level of sensory block attained till the sensation had regressed by 2 segments. Duration of sensory blockade was taken as the time from the injection of study drug till the return of sensation at S1 dermatomal level.

Quality of motor block was assessed by modified Bromage scale. Onset of motor blockade was defined as the time taken from the completion of injection of the study drug till the subject developed Bromage-1. Time taken for maximum motor blockade was defined as the time from the completion of injection of the study drug to the maximum motor blockade attained. Total duration of motor blockade was the time taken from the time of injection till the subject attained complete motor recovery (Bromage $=0$ ).

Hemodynamic parameters were recorded every 2 min for $10 \mathrm{~min}$, every $5 \mathrm{~min}$ till $40 \mathrm{~min}$, then every $10 \mathrm{~min}$ till the end of surgery. Adverse effects like hypotension (reduction in SBP > $20 \%$ from basal value or SBP $<90 \mathrm{mmHg}$ ), bradycardia (HR $<60$ beats/min) postoperative nausea and vomiting, sedation if any, were noted and treated appropriately. The total dose of vasopressor (mephenteramine) required to treat hypotension, and the number of parturients requiring atropine to treat bradycardia were noted.

Neonatal assessment was done using APGAR scores at 1 and $5 \mathrm{~min}$ by the attending pediatrician. Postoperative pain was assessed using visual analogue scale (VAS) at $30 \mathrm{~min}$, then hourly for the next $6 \mathrm{~h}$, and 2 hourly till 24 h. Time to first rescue analgesic request was recorded. Total duration of analgesia was defined as the time from intrathecal injection to the first request of analgesic (or VAS > 5) which consisted of inj diclofenac $75 \mathrm{mg}$ with a maximum daily dose of $150 \mathrm{mg}$.

\section{Statistical analysis:}

Sample size calculation was based on our pilot study. An estimated number of 26 parturients per group were necessary to achieve an $80 \%$ power, based on a simple stratified two-sample 95\% confidence interval for group comparison. To compensate for the dropouts from the study and also to make sure that the sampling size was adequate, a total of 60 parturients were selected.

Descriptive statistics such as mean and standard deviation (SD) were used for continuous variables, median and range for non-normally distributed variables and categorical variables were summarized using percentages.

Independent samples t-test was applied to compare the mean difference between two groups for continuous variables like HR, SBP, DBP and MAP. Repeated measures ANOVA was applied when data measurement was made several times to find out differential increase or decrease across the two groups. Chi-square test $\left(\chi^{2}\right.$ test) was used as a statistical test of significance for categorical variables. When the sample sizes were small i.e., if the expected frequencies were less than 5, Fisher's exact test was used. All variables are presented through tables and graphs.

Data were entered into Microsoft Excel and analyzed using SPSS Statistics Version 22 for Windows. A $\mathrm{p}<0.05$ was considered significant and $\mathrm{p}<0.01$ was considered highly significant.

\section{RESULTS}

In the present study, the parturients in Group-B and Group-L were comparable with respect to demographic characteristics like age, height and weight (Table 1). All parturients completed the study. The mean duration of surgery in Group-B was $49.07 \pm$ $9.78 \mathrm{~min}$ and in Group-L was $48.63 \pm 9.67 \mathrm{~min}$. 
comparative study of isobaric levobupivacaine and hyperbaric bupivacaine

Table 1: Demographic details of the parturients

\begin{tabular}{lccc}
\multicolumn{1}{c}{$\begin{array}{c}\text { Demographic } \\
\text { criteria }\end{array}$} & $\begin{array}{c}\text { Group-B } \\
(\mathbf{n}=\mathbf{3 0})\end{array}$ & $\begin{array}{c}\text { Group-L } \\
(\mathbf{n}=\mathbf{3 0})\end{array}$ & p value \\
\hline Mean age $(\mathrm{y})$ & $24.63 \pm 2.73$ & $25.43 \pm 3.49$ & $0.976(\mathrm{NS})$ \\
\hline Mean height $(\mathrm{cm})$ & $156 \pm 4.26$ & $156.77 \pm 4.17$ & $0.67(\mathrm{NS})$ \\
\hline Mean weight $(\mathrm{kg})$ & $60.13 \pm 5.5$ & $59.37 \pm 5.86$ & $0.19(\mathrm{NS})$ \\
\hline $\begin{array}{l}\text { Mean duration } \\
\text { LSCS (min) }\end{array}$ & $49.07 \pm 9.78$ & $48.63 \pm 9.67$ & $0.91(\mathrm{NS})$ \\
\hline Data expressed as Mean \pm Standard deviation $(S D), N S$ - not significant $(p>0.05)$
\end{tabular}

Table 2: Sensory block characteristics in groups

\begin{tabular}{lccc}
$\begin{array}{c}\text { Sensory block } \\
\text { characteristics }\end{array}$ & $\begin{array}{c}\text { Group-B } \\
\text { (Mean } \pm \text { SD) }\end{array}$ & $\begin{array}{c}\text { Group-L } \\
\text { (Mean } \pm \text { SD) }\end{array}$ & p value \\
$\begin{array}{l}\text { Time of onset of sensory } \\
\text { block (sec) }\end{array}$ & $43.73 \pm 8.24$ & $153.6 \pm 36.27$ & $<0.001(\mathrm{HS})$ \\
\hline $\begin{array}{l}\text { Highest level of sensory } \\
\text { block (T dermatome) }\end{array}$ & $\mathrm{T} 4.23 \pm 1.192$ & $\mathrm{~T} 5.47 \pm 1.442$ & $0.77(\mathrm{NS})$ \\
\hline $\begin{array}{l}\text { Time taken to achieve } \\
\text { highest level of sensory } \\
\text { block (min) }\end{array}$ & $4.03 \pm 1.15$ & $5.6 \pm 1.17$ & $0.023(\mathrm{~S})$ \\
\hline $\begin{array}{l}\text { Two segment regression } \\
\text { time (min) }\end{array}$ & $114.47 \pm 9.28$ & $129.17 \pm 13.33$ & $<0.001(\mathrm{HS})$ \\
\hline $\begin{array}{l}\text { Time taken for sensory } \\
\text { regression to S1 level (min) }\end{array}$ & $242.17 \pm 21.12$ & $164.17 \pm 14.02$ & $<0.001(\mathrm{HS})$ \\
\hline $\begin{array}{l}\text { Total duration of analgesia } \\
\text { (min) }\end{array}$ & $332.83 \pm 22.88$ & $298 \pm 17.84$ & $0.04(\mathrm{~S})$ \\
\hline
\end{tabular}

Data expressed as Mean \pm Standard deviation (SD), NS- not significant $(p>0.05)$ $\pm 22.88 \mathrm{~min}$ ) compared

to Group-L (298 \pm $17.84 \mathrm{~min})$.

The mean time of onset of motor block was significantly faster $(\mathrm{p}<0.001)$ in Group-B $(41.87 \pm 10.48 \mathrm{sec})$ compared to Group-L $(142.17 \pm 12.91 \mathrm{sec})$. The mean time to reach maximum motor block was $197.6 \pm$ $24.52 \mathrm{sec}$ in Group-B and $498.17 \pm 114.10$ sec in Group-L; the difference was highly significant ( $\mathrm{p}<$ 0.001).The total duration of motor block was significantly prolonged in Group-B $(297.83 \pm 27.31 \mathrm{~min})$ compared to Group-L $(144.5 \pm 18.21 \mathrm{~min})$.

No significant difference was observed in the APGAR scores between the groups at

The difference was not statistically significant $(\mathrm{p}=0.91)$.

The salient features regarding sensory and motor block are given in Tables 2 and 3 respectively. The time of onset of sensory block and the time taken to achieve highest level of sensory block was significantly faster in GroupB compared to Group-L, but the highest level of sensory block was comparable in both the groups $(p>0.05)$. The mean time for two segment sensory regression was significantly prolonged in Group-L $(129.17 \pm 13.33 \mathrm{~min})$ compared to Group-B $(114.47 \pm 9.28 \mathrm{~min})$. The time taken for regression of sensory blockade was more prolonged in Group-B than in Group$\mathrm{L}(\mathrm{p}<0.001)$. The total duration of analgesia was significantly prolonged in Group-B (332.83 both 1 and 5 min intervals $(\mathrm{p}>0.05)$

Table 4 shows the incidence of adverse effects observed in both the groups. There was a higher incidence of adverse effects like hypotension, bradycardia and shivering in Group-B compared to Group-L. Ramsay sedation score was used for sedation assessment which was $<$ or $=2$ in both the groups $(p>0.05)$.

The average dose of vasopressor required to treat hypotension was $8.57 \pm 1.10 \mathrm{mg}$ and $6 \mathrm{mg}$ in Group-B and Group-L respectively. The number of parturients requiring atropine for the treatment of bradycardia was 4 vs. 2 in Group-B and Group-L respectively.

Regarding hemodynamic changes, mean heart rate was comparable in both the groups ( $p>$ $0.05)$. Significant difference was observed in 
Table 3: Motor block characteristics in groups $B$ and $L$

\begin{tabular}{lccc}
\multicolumn{1}{c}{ Motor block data } & $\begin{array}{c}\text { Group-B } \\
\text { (Mean } \pm \text { SD) }\end{array}$ & $\begin{array}{c}\text { Group-L } \\
\text { (Mean } \pm \text { SD) }\end{array}$ & p value \\
\hline $\begin{array}{l}\text { Time to onset of motor block) } \\
\text { (Bromage grade 1) }(\mathrm{sec})\end{array}$ & $41.87 \pm 10.48$ & $142.17 \pm 12.91$ & $<0.001(\mathrm{HS})$ \\
\hline $\begin{array}{l}\text { Time taken for maximum motor } \\
\text { block (sec) }\end{array}$ & $197.6 \pm 24.52$ & $498.17 \pm 114.10$ & $<0.001(\mathrm{HS})$ \\
\hline $\begin{array}{l}\text { Total duration of motor block } \\
\text { (min) }\end{array}$ & $297.83 \pm 27.31$ & $144.5 \pm 18.21$ & $<0.001(\mathrm{HS})$ \\
\hline
\end{tabular}

HS- Highly significant $(p<0.01)$

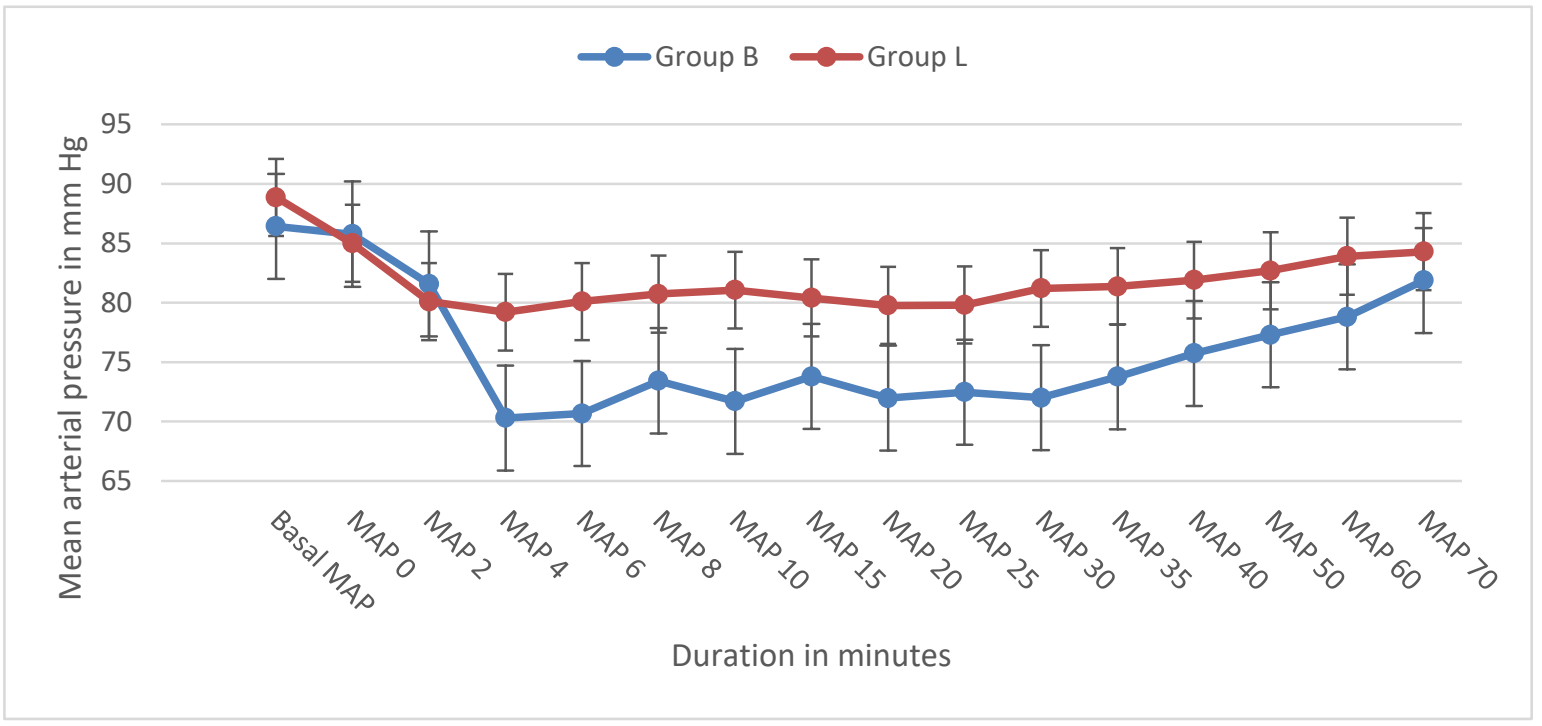

Figure 1: Changes in mean arterial blood pressure (MAP) between the groups

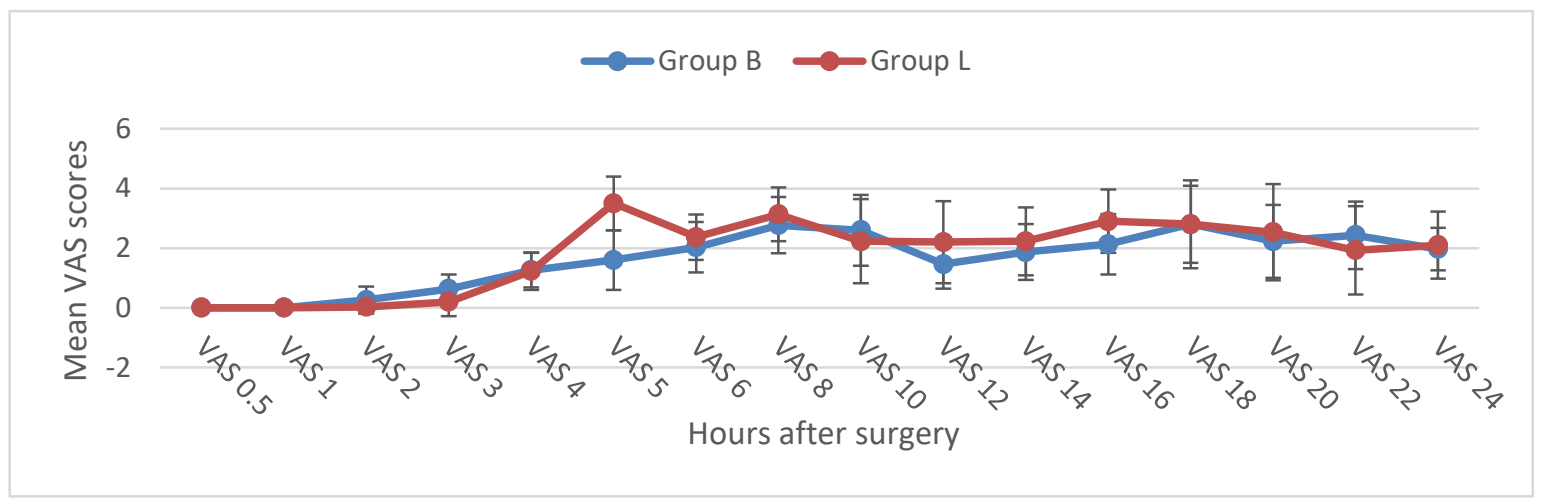

Figure 2: Postoperative mean VAS scores for $24 \mathrm{~h}$ 
comparative study of isobaric levobupivacaine and hyperbaric bupivacaine

Table 4: Incidence of adverse effects

\section{Adverse effects Group-B Group-L}

\begin{tabular}{lll} 
Hypotension & 7 & 3 \\
\hline Bradycardia & 4 & 2 \\
\hline Shivering & 2 & 0 \\
\hline Nausea and vomiting & 2 & 1 \\
\hline Pruritus & 0 & 0 \\
\hline \multicolumn{2}{l}{ Data expressed as numbers $(n)$}
\end{tabular}

mean arterial blood as shown in the Figure 1, with significant fall in mean arterial blood pressure in parturients in Group-B.

Except the $5^{\text {th }}$ hour recording, mean VAS scores in both the groups in the first $24 \mathrm{~h}$ postoperative period were comparable (Figure 2).

\section{DISCUSSION}

In this era of advanced obstetric care, spinal anesthesia continues to be the commonest technique relied upon by most anesthesiologists. Its advantages include ease and reliability of technique, rapid onset of sensory and motor blockade. ${ }^{11}$ Careful prevention of potential complications must be sought to maintain high maternal and neonatal safety. Although hyperbaric local anesthetics in obstetric anesthesia have excellent record of safety, their use is not absolutely without risks. ${ }^{12}$

All concentrations of plain bupivacaine are hypobaric when measured at 37 degrees. ${ }^{13}$ Plain levobupivacaine may be regarded as truly isobaric with respect to cerebrospinal fluid (CSF) of pregnant women since their specific gravity is very similar. ${ }^{14}$ The increased density of levobupivacaine may be attributable to its higher sodium ion content and higher osmolality. ${ }^{13}$ This isobaricity may produce a more predictable spread of spinal anesthesia. Theoretically, the highest dermatomal level of analgesia produced from isobaric local anesthetics should be independent of patient position or gravity. The spread of isobaric levobupivacaine in women at term does not depend on gravitational forces as studied by Gori $\mathrm{F}$ et al. ${ }^{14}$

Combination of opioid with local anesthetics is associated with improved anesthesia and analgesia. Intrathecal fentanyl added to low dose local anesthetics produces synergistic effects without affecting sympathetic blockade or delaying discharge from hospital. It allows for the use of low dose of local anesthetics, which contributes to better hemodynamics. ${ }^{5,11}$

Researchers using $0.5 \%$ levobupivacaine alone and $0.5 \%$ levobupivacaine with fentanyl during urological surgery showed that levobupivacaine with fentanyl was as effective as levobupivacaine alone. They found that the highest level of sensory block was similar between the two groups and that the resolution of motor block was faster in the combination group. ${ }^{15,16,17}$ Less pronounced motor blockade by levobupivacaine than by racemic bupivacaine, irrespective of the type and dose of opioid used, was well demonstrated by Bremerich $\mathrm{DH}$ et al., with fixed intrathecal doses of $10 \mathrm{mg}$ of both drugs for elective LSCS. $^{18}$

Parpaglioni $\mathrm{R}$ et al. have shown that the minimum local anesthetic dose (MLAD) of levobupivacaine was $4.73 \mathrm{mg} .{ }^{19}$ Bouvet $\mathrm{L}$ et al. demonstrated that the median effective dose (ED50) of levobupivacaine was $6.2 \mathrm{mg}$ and the dose needed for the desired effect in $95 \%$ of population exposed was $12.9 \mathrm{mg} .{ }^{20}$ Gunusen I et al. studied various doses of levobupivacaine and fentanyl combination for LSCS and stated that $10 \mathrm{mg}$ levobupivacaine with $10 \mu \mathrm{g}$ fentanyl provides $100 \%$ effective anesthesia but hypotension rate was higher. ${ }^{21,22,23,24}$ So in our study, low dose of levobupivacaine $(8 \mathrm{mg})$, which was in between the doses mentioned above, combined with fentanyl was used.

The present study demonstrates that isobaric levobupivacaine + fentanyl combination produced adequate surgical anesthesia for cesarean section. This combination delayed the onset of sensory block and achieved a lesser maximal sensory level than hyperbaric bupivacaine + fentanyl combination. Time taken to produce this maximal level of sensory analgesia was also slower. Our findings correlate with the results obtained by earlier researchers. ${ }^{12,23} \mathrm{We}$ observed that two segment sensory regression time with this spinal drug 
combination was prolonged, but regression to S1 level was faster compared to bupivacaine group. Our results correlate with earlier studies. $^{23,25}$ Though the total duration of analgesia was shorter with levobupivacaine, 24 $\mathrm{h}$ postoperative VAS scores were not statistically significant compared to bupivacaine group.

Motor block characteristics with respect to onset, maximum grading and total duration were better and sustained in Group-B compared to Group-L and the findings were consistent with the results obtained by earlier studies. ${ }^{12,26,27}$ Thus isobaric levobupivacaine produces motor block of shorter duration yet sufficient for cesarean sections and favors early postoperative ambulation, preventing postoperative complications like DVT and thromboembolic phenomena.

Significant difference was observed in mean arterial pressures between two groups at various time intervals, with a significant fall in MAP in Group-B. Similar findings were found in earlier studies. $^{19,24}$

Incidence of adverse effects was significantly higher in bupivacaine group. ${ }^{12}$
Both agents produced similar neonatal effects with comparable APGAR scores at 1 and 5 min. Our results correlate with the study by Misirlioglu $\mathrm{K}$ et al. $^{27}$ Lirk $\mathrm{P}$ et al. evaluated neonatal effects by using three different intrathecal local anesthetic agents (bupivacaine, ropivacaine and levobupivacaine) and found no difference in the outcome as assessed by APGAR score and $\mathrm{pH}$ of arterial blood from the umbilical cord. ${ }^{28}$

\section{CONCLUSION}

We conclude that spinal anesthesia with either hyperbaric bupivacaine $8 \mathrm{mg}$ or isobaric levobupivacaine $8 \mathrm{mg}$, in combination with 25 $\mu \mathrm{g}$ fentanyl, provide effective surgical anesthesia for elective caesarean section. However, with isobaric levobupivacaine + fentanyl combination, motor block is of shorter duration and there is lower incidence of hemodynamic instability, hence it can be an attractive alternative to hyperbaric bupivacaine.

Conflict of interest: Nil declared by the authors

Authors' contribution:

DG: Concept, review of articles, manuscript editing SA: Review of articles, preparation of manuscript NPMI: Conduction of the study, data collection

\section{REFERENCES}

1. Jenkins JG, Khan MM. Hemthesia for Caesarean section: A survey in a UK region from 1992 to 2002. Anaesthesia. 2003;58(11):1114-8. [PubMed] DOI: 10.1046/i.13652044.2003.03446.x

2. Barash $P$, Cullen BF, Stoelting RK, Cahalan M, Stock MC, Ortega R. Clinical Anesthesia. $7^{\text {th }}$ ed. Lippincott Williams and Wilkins; 2013.

3. Kuhnert BR, Zuspan KJ, Kuhnert $P M$, Syracuse CD, Brown DE. Bupivacaine disposition in mother, fetus, and neonate after spinal anesthesia for cesarean section. Anesth Analg. 1987;66(5):407-12. [PubMed] DOI: 10.1213/00000539198705000-00006

4. Russell IF. Technique of anaesthesia for caesarean sections. Raising the standards: a compendium of audit recipes; 2006. p.166-7.
5. Agarwal A, Kishore K. Complications and controversies of regional anesthesia: $A$ review. Indian J Anaesth. 2009 Oct;53:54353. [PubMed]

6. Choi DH, Ahn HJ, Kim MH. Bupivacaine-sparing effect of fentanyl in spinal anesthesia for cesarean delivery. Reg Anesth Pain Med. 2000;25(3):240-5. [PubMed] DOI: $\underline{10.1016 / \mathrm{s} 1098-}$ 7339(00)90005-1

7. Corby MP, Bach AB. Transient radicular irritation (TRI) after spinal anaesthesia in day-care surgery. Acta Anaesthesiol Scand. 1998;42(4):425-9. [PubMed] DOI: 10.1111//.13996576.1998.tb05136.x

8. Bucklin BA, Hawkins JL, Anderson JR, Ullrich FA. Obstetric anesthesia workforce survey: twenty-year update. Anesthesiology. 2005;103:645-53. [PubMed] DOI:
$10.1097 / 00000542-200509000$ $\underline{00030}$

9. Bajwa SJS, Kaur J. Clinical profile of Levobupivacaine in regional anesthesia: A systematic review. J Anaesthesiol Clin Pharmacol. 2013;29(4):530-8. [PubMed] DOI: 10.4103/0970-9185.119172

10. Foster $\mathrm{RH}$, Markham $\mathrm{A}$. Levobupivacaine: a review of its pharmacology and use as a local anaesthetic. Drugs. 2000;59(3):551-79. [PubMed] DOI: 10.2165/00003495-20005903000013

11. Tsen LC. Anesthesia for cesarean delivery. Chapter 26. In: Chestnut's Obstetric Anesthesia: Principles and Practice, Chestnut DH (ed.) Philadelphia: Elsevier Saunders; 2014. p545-603.

12. Guler $G$, Cakir G, Ulgey A, Ugur F, Bicer C, Gunes I, et al. A comparison of spinal anesthesia 
with levobupivacaine and hyperbaric bupivacaine for cesarean sections: a randomized trial. Open J Anesthesiol. 2012;2(3):84-9. DOl: 10.4236/ojanes.2012.23020

13. McLeod GA. Density of spinal anaesthetic solutions of bupivacaine, levobupivacaine, and ropivacaine with and without dextrose. $\mathrm{Br} \mathrm{J}$ Anaesth. 2004;92(4):547-51. [PubMed] DOI: 10.1093/bja/aeh094

14. Gori F, Corradetti F, Cerotto V, and Peduto VA. Influence of positioning on plain levobupivacaine spinal anesthesia in cesarean section. Anesthesiol Res Pract. 2010;2010. pii: 212696. [PubMed] DOI: 10.1155/2010/212696

15. Lee YY, Muchhal K, Chan CK, Cheung AS. Levobupivacaine and fentanyl for spinal anaesthesia: a randomized trial. Eur J Anaesthesiol. 2005;22(12):899903. [PubMed] DOI: 10.1017/S0265021505001523

16. Cuvas $O$, Basar $H$, Yeygel $A$, Turkyilmaz E, Sunay MM. Spinal anesthesia for transurethral resection operations: levobupivacaine with or without fentanyl. Middle East J Anesthesiol. 2010;20(4):547-52. [PubMed]

17. Bidikar M, Mudakanagoudar MS, Santhosh MC. Comparison of intrathecal levobupivacaine and levobupivacaine plus fentanyl for cesarean section. Anesth Essays Res. 2017;11(2):495-8. [PubMed] DOI: 10.4103/aer.AER $16 \quad 17$

18. Bremerich DH, Fetsch N, Zwissler $B C$, Meininger D, Gogarten $W$,
Byhahn C. Comparison of intrathecal bupivacaine and levobupivacaine combined with opioids for Caesarean section. Curr Med Res Opin. 2007;23(12):3047$54 . \quad$ [PubMed] DOI: 10.1185/030079907X242764

19. Parpaglioni $R$, Frigo $M$, Lemma $A$, Sebastiani M, Barbati G, Celleno D. Minimum local anaesthetic dose (MLAD) of intrathecal levobupivacaine and ropivacaine for Caesarean section. Anaesthesia. 2006;61(2):110-5. [PubMed] DOI: 10.1111/j.1365-2044.2005.04380.x

20. Bouvet L, Da-Col X, Chassard D, Daléry F, Ruynat L, Allaouchiche B, et al. $\mathrm{ED}_{50}$ and $\mathrm{ED}_{95}$ of intrathecal levobupivacaine with opioids for caesarean delivery. $\mathrm{Br} \mathrm{J}$ Anaesth. 2011;106(2):215-20. [PubMed] DOI: 10.1093/bja/aeq296

21. Gunusen I, Karaman S, Sargin A, Firat V. A randomized comparison of different doses of intrathecal levobupivacaine combined with fentanyl for elective cesarean section: prospective, double-blinded study. J Anesth. 2011;25(2):20512. [PubMed] DOI: $10.1007 / \mathrm{s} 00540-$ 011-1097-4

22. Lee YY, Warwick D, Siu Y, John TC Liu, Tony Gin. The median effective dose of bupivacaine, levobupivacaine, and ropivacaine after intrathecal injection in lower limb surgery. Anesth Analg. 2009 Oct;109(4):1331-4. [PubMed] DOI: 10.1213/ane.0b013e3181b1912b

23. Glaser C, Marhofer P, Zimpfer G, Heinz M, Sitzwohl C, Kapral S, et al. Levobupivacaine versus racemic bupivacaine for spinal anesthesia.
Anesth Analg. 2002;94(1):194-8. [PubMed] DOI: 10.1097/00000539200201000-00037

24. Fattorini F, Ricci Z, Rocco A, Romano R, Pascarella MA, Pinto G. Levobupivacaine versus racemic bupivacaine for spinal anaesthesia in orthopaedic major surgery. Minerva Anestesiol. 2006;72(78):637-44. [PubMed]

25. Prabha $P$, Shreyavathi $R$, Raghavendra RS, Akshatha Rao. Comparative study of intrathecal bupivacaine and levobupivacaine with fentanyl for caesarean section. Sch J App Med Sci. 2014;2(4B):1255-9. [Free Full Text]

26. Kaur K, Johar $S$, Kumar $A$, Jain $M$, Kumar P, Singh A. A comparative study of intrathecal bupivacaine and levobupivacaine for patients undergoing caesarean section. Int J Adv Med. 2019;6(6):1792-7. DOI: 10.18203/2349-3933.ijam20195229

27. Misirlioglu K, Sivrikaya GU, Hanci A, Yalcinkaya A. Intrathecal lowdose levobupivacaine and bupivacaine combined with fentanyl in a randomized controlled study for caesarean section: blockade characteristics, maternal and neonatal effects. Hippokratia. 2013;17(3):262-7. [PubMed]

28. Lirk $P$, Kleber $N$, Mitterschiffthaler G, Keller C, Benzer A, Putz G. Pulmonary effects of bupivacaine, ropivacaine, and levobupivacaine in parturients undergoing spinal anaesthesia for elective caesarean delivery: A randomised controlled study. Int J Obstet Anesth. 2010;19(3):287-92. [PubMed] DOI: 10.1016/j.ijoa.2009.03.015. 